\title{
Overcoming barriers to implementing brief intervention: a knowledge transfer partnership
}

\author{
Paul Jordan*, Jonathan Shepherd, Simon Moore \\ From International Network on Brief Interventions for Alcohol and Other Drugs (INEBRIA) Meeting 2013 \\ Rome, Italy. 18-20 September 2013
}

Cardiff University, the Welsh Government and Public Health Wales are working together to implement screening and brief interventions across a variety of health and community settings through a unique collaboration; a Knowledge Transfer Partnership (KTP). Previous research has uncovered both barriers and facilitators to implementation. This KTP seeks to build upon this work and translate the research into practice. The Have-a-Word social marketing initiative, the first of its kind, was launched in 2013 in Wales and seeks to specifically address the barriers to implementing SBI. To date over 2000 health and community professionals have received training ${ }^{1}$. This paper demonstrates how social marketing has been used to overcome barriers to implementing screening and brief interventions across a variety of health and community settings in Wales. The Have-a-Word campaign, currently being rolled out across Wales, seeks to manage the image of screening and brief interventions and encourage those who have received training to deliver brief interventions. Evaluation of the Welsh model shows that many health and community professionals who received training continue to view a formal screening tool such as FAST as a barrier to successfully implementing the SBI model in specific settings. Social marketing has helped overcome barriers to delivery (some nurses commented that they felt part of an SBI community which empowered them). A more pragmatic approach to screening is required since the formal screening tool was dissuading some professionals from delivering brief interventions at all. Social marketing campaigns can help manage the image of brief interventions however sustaining those who have received training remains a challenge and continued support and encouragement are needed.

\footnotetext{
* Correspondence: JordanPT@cardiff.ac.uk

Violence and Society Research Group, Cardiff University, Cardiff, UK
}

${ }^{1}$ This includes maxillofacial and trauma clinic nurses, midwives, health visitors, dieticians, custody sergeants, youth workers and practice nurses.

Published: 4 September 2013

doi:10.1186/1940-0640-8-S1-A38

Cite this article as: Jordan et al:: Overcoming barriers to implementing brief intervention: a knowledge transfer partnership. Addiction Science \& Clinical Practice 2013 8(Suppl 1):A38.

Submit your next manuscript to BioMed Central and take full advantage of:

- Convenient online submission

- Thorough peer review

- No space constraints or color figure charges

- Immediate publication on acceptance

- Inclusion in PubMed, CAS, Scopus and Google Scholar

- Research which is freely available for redistribution

Submit your manuscript at www.biomedcentral.com/submit
() Biomed Central
() Biomed Central

C 2013 Jordan et al; licensee BioMed Central Ltd. This is an Open Access article distributed under the terms of the Creative Commons Attribution License (http://creativecommons.org/licenses/by/2.0), which permits unrestricted use, distribution, and reproduction in any medium, provided the original work is properly cited. 